DOI: https://doi.org/10.15407/emodel.43.03.017

UDC 621.01:62-251:62-762

S.S. Shevchenko, PhD in Technical Sciences

Pukhov Institute for Modelling in Energy Engineering

of the National Academy of Sciences of Ukraine

15, General Naumov Str. Kiev, 03164, Ukraine

E-mail: s.shevchenko@united.productions

\title{
Mathematical modelling of dynamic system rotor - groove seals
}

Groove seals are considered as hydrostatic bearings that capable of effectively damping rotor vibrations. In order to determine the dynamic characteristics, a model of the rotor-groove seals system is considered. The radial forces and moments in groove seals had been estimated. Expressions of joint radial-angular rotor vibrations in groove seals had been obtained. Formulas had been proposed for constructing amplitude and phase frequency characteristics. An example of calculating the dynamic characteristics of a centrifugal machine rotor model is given.

K e y w o r d s: seals-bearings, radial-angular oscillations, frequency characteristics.

The vibratory condition of the centrifugal machine rotors is determined by the dynamic characteristics of groove seals. Centrifugal pumps and compressors are widely used in all industries. A steady upward trend of the operational parameters is peculiar to them: supplies, pressure and speeds, i.e. to the concentration of increasingly higher capacities in individual units. For example, main circulation pump flow of nuclear power plants is $20000 \mathrm{~m}^{3} / \mathrm{h}$, high-speed pump flow is $60 \mathrm{MPa}$ [1]. High-pressure centrifugal compressors build up a downstream pressure of up to $180 \mathrm{MPa}$. The rotor speed of rocket turbopump assemblies (TPA) reaches $3500 \mathrm{~s}^{-1}$ and is limited only with impeller strength (maximum allowable peripheral speed of impeller rim $-450 \mathrm{~m} / \mathrm{s}$ ). TPA capacity is measured in hundreds of megawatts with an extremely low weight and size specifications. Among all types of the impeller machines of engine and power plants, TPAs have the highest specific capacity $50-150 \mathrm{~kW} / \mathrm{kg}$.

The distinguishing characteristics of centrifugal machine is that the tasks of vibration reliability and sealing are interrelated and, in most cases, can be satisfactorily accomplished through the correct selection of the groove seal construction. Therefore, when selecting the construction of groove seals, not 

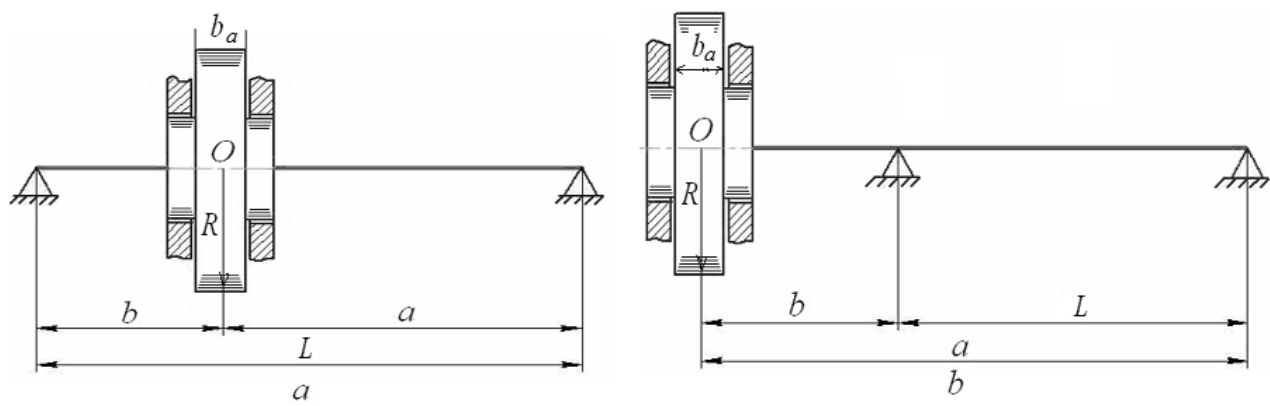

Fig. 1. Typical diagrams of single-disk rotor in groove seals: $a$-with a disk between the bearings ( $P-1, P-1 c$ models); $b$ - overhung ( $P-2$ model) with mass $m$, radius $R$ and effective thickness $b_{e}$

only their designated purpose - to reduce volume losses should be taken into account, but also their no less important function - to ensure the required vibration characteristics of rotor.

Problem statement. Two typical diagrams of single-disk rotor: with the disk between fixed bearings (Fig. 1, $a$ ) of asymmetrical ( $P-1$ model), symmetrical $l_{1}=l_{2}(P-1 c$ model) and overhung (Fig. 1, $b, P-2$ model) are considered. Identical groove seals are situated from both sides of the disk (impeller).

The first diagram imitates the rotor of single-stage pump with double-entry impeller and the second - the rotor of overhang pump. In both diagrams radial displacements of disk are accompanied with its rotation in the plane of defected shaft axis. Inertial resistance to rotation is characterized with the corresponding gyroscopic moment of disk. Rotor mass is concentrated in the center of disk masses and a weightless elastic shaft rotates in fixed bearings.

The rotor is statically and dynamically unbalanced: center of mass is displaced from the mechanical center for the amount of eccentricity $a\left(a_{x}, a_{y}\right)$ that stands for static unbalance. The main central axes of disk inertia due to fit tilt or other instrument accuracy are deviated from the principal shaft axes of section (main flexural shaft axes) to angles $\gamma_{x}, \gamma_{y}$, characterizing dynamic unbalance of the rotor. Unbalance parameters are considered to be preset small values.

Analysis of last publications. While developing centrifugal pumps for any parameters, except for workout of economic wetted part, high-priority tasks are vibration reduction, ensuring the desired reliability and service life of bearings and drive couplings, development of durable and sufficiently airtight seals [2].

In centrifugal pumps up to $100 \%$ of the power intake is lost for leakage through groove seals of impellers and autodump system of axial forces [3]. 
Energy of volumetric losses can be converted into net energy, if the groove seals are used as hydrostatic bearings able to have not only high radial rigidity but also to effectively damp the rotor fluctuations [4]. In this case leakage energy can not only ensure necessary load-carrying capacity of bearings but also importantly to reduce the rotor vibrations to the acceptable level even if there is a significant unbalance [5]. Environmental effect is especially considerable if there are existing steep velocity and pressure gradients, which is peculiar to close gaps of the groove seals, on which high pressure differentials are restricted and one of the walls belongs to the rotating and vibrating rotor [6].

As it is mentioned in the paper [7], rotor and groove seals are a closed hydro mechanical. This is the reason for key feature and complexity of the problem of centrifugal machine rotor dynamics. The seals not only change critical frequencies of rotor but also have significant influence on the amplitudes of its forced oscillations and stability thresholds [8].

The dynamic characteristics of groove seals as intermediate supports have been studied in the paper [9], in which linearized expressions of radial hydrodynamic forces and moments acting on the rotor on the part of fluid flow in gap of groove seal. The power characteristics are determined by the geometric and operating parameters of the seals: initial taper and radial clearance, length and average radius of the channel, throttled pressure drop, rotor speed, swirling flow at the gap inlet, physical properties of the fluid. Analysis of the influence of groove seals on the rotor dynamics allows choosing their design so that in the entire operating range the vibration level of the rotor is within the acceptable limits [10].

However, the problems of rotor dynamics in groove seals are insufficiently explored as to solve them it is necessary to know the hydrodynamic characteristics of groove seals and this is a separate problem in the hydrodynamics of three-dimensional unsteady viscous fluid flows in annular channels, whereof walls rotate and simultaneously perform radial-angular oscillations.

Since the problems of the rotor dynamics without groove seals have been mainly solved, analyze oscillatory processes caused by the hydrodynamic characteristics of seals.

Dynamic rotor - groove seals system. Gap throttles separate spaces, where the sealing area is under different pressures. The flow rate is limited due to the consumption of potential pressure energy to overcome local resistances, friction resistance along the length of the channel, and sometimes on inertial resistance. The higher this consumption, the lower potential energy is converted into kinetic energy of the flow, the lower average fluid velocity in the channel and its flow rate. Thus, the groove seals do not completely eliminate, but only limit the flow.

A simplified structural diagram of the rotor - groove seals system is shown in Fig. 2. Radial $(x, y)$ and angular $\left(\vartheta_{x}, \vartheta_{y}\right)$ oscillations of the rotor are 


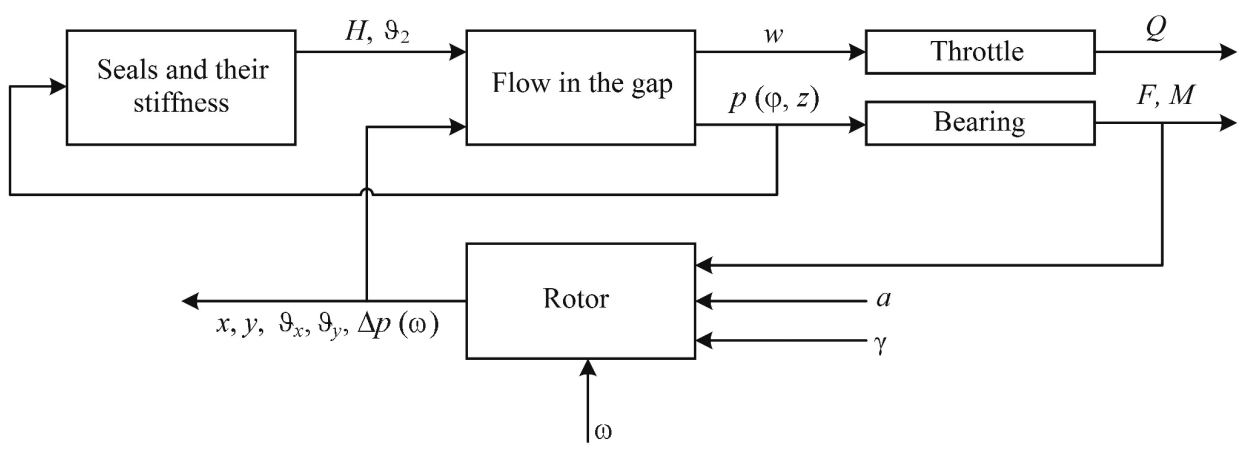

Fig. 2. Structural diagram of the hydromechanical rotor - groove seal system

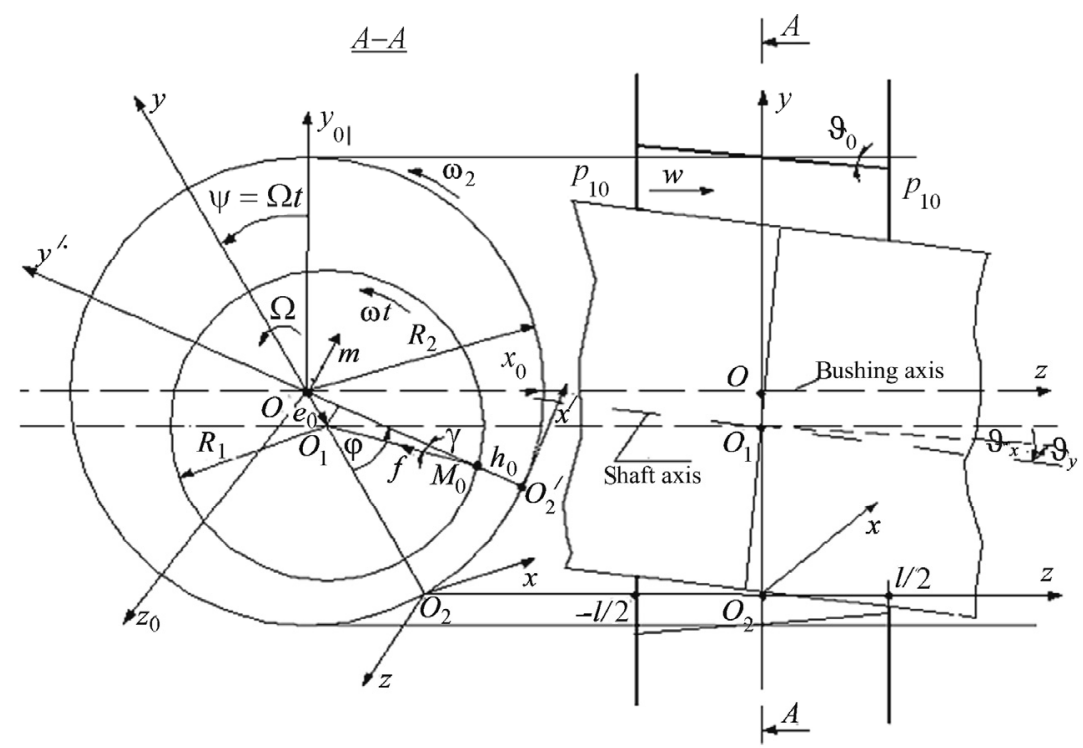

Fig. 3. Design diagram of the groove seal with a movable bushing

largely determined by hydrodynamic forces $(F)$ and moments $(M)$ arising in the sealing gaps (in annular throttles), and the very forces and moments depend on the nature of rotor movement. There is another feedback between geometric shape of the gap (average radial gap $H$ and taper $\vartheta_{2}$ ) and pressure in the gap $p(z, \varphi)$ : deformations of the sealing rings are determined by pressure distribution, and the latter is very sensitive to changes in size and shape of the gap.

Radial forces and moments in groove seals. Fig. 3 shows a model of the groove seal that is an annular throttle formed by inner cylinder (shaft) with a small taper angle $\vartheta_{A}$ and outer cylinder (sleeve) with a taper angle $\vartheta_{B}$; total taper angle of the channel $\vartheta_{0}=\vartheta_{B}-\vartheta_{A}$. Taper parameter of the channel $\theta_{0}=\vartheta_{0} \mathrm{l} / 2 \mathrm{H},\left|\theta_{0}\right| \leq 1$. 
Shaft and bushing rotate around their own axes with the frequencies of their own rotation $\omega_{1}, \omega_{2}$. The axes rotate around the fixed center $O$ with precession frequencies $\Omega_{1}, \Omega_{2}$, and also perform radial and angular oscillations. The paper has provided an assessment of the force characteristics for laminar and turbulent flow regimes taking into consideration local resistances and in view of flow swirl at the gap inlet [1].

Projections onto the fixed axes of the coordinates of individual components of hydrodynamic forces and moments

$$
\begin{gathered}
F_{s(x, y)}=F_{g(x, y)}+F_{d(x, y)}+F_{p(x, y)}, \\
M_{s(x, y)}=M_{g(x, y)}+M_{d(x, y)}+M_{p(x, y)},
\end{gathered}
$$

arising in one groove seal and referred to the rotor mass, are written as:

forces and moments due to fluid inertia, -

$$
\begin{gathered}
\frac{F_{g x}}{m}=-k_{g}\left[\ddot{x}-\frac{12 \theta_{0} q_{0}}{H l(2-n)} \dot{x}+\kappa \omega_{a} \dot{y}-\frac{2}{15} \kappa \omega_{a} \theta_{0} \frac{l}{2} \dot{\vartheta}_{x}\right], \\
\frac{F_{g y}}{m}=-k_{g}\left[\ddot{y}-\frac{12 \theta_{0} q_{0}}{H l(2-n)} \dot{y}-\kappa \omega_{a} \dot{x}-\frac{2}{15} \kappa \omega_{a} \theta_{0} \frac{l}{2} \dot{\vartheta}_{y}\right], \\
\frac{M_{g x}}{m}=-k_{g} \frac{l}{30}\left(\frac{l}{2} \ddot{\vartheta}_{x}+2 \kappa \omega_{a} \theta_{0} \dot{x}+\kappa \omega_{a} \frac{l}{2} \dot{\vartheta}_{y}\right), \\
\frac{M_{g y}}{m}=-k_{g} \frac{l}{30}\left(\frac{l}{2} \ddot{\vartheta}_{y}+2 \kappa \omega_{a} \theta_{0} \dot{y}-\kappa \omega_{a} \frac{l}{2} \dot{\vartheta}_{x}\right) ;
\end{gathered}
$$

forces and moments due to displacement flow, -

$$
\begin{gathered}
\frac{F_{d x}}{m}=-k_{d}\left[\dot{x}+\kappa \omega_{a} y-\frac{l}{5} \theta_{0}\left(\kappa \omega_{a} \vartheta_{x}-\dot{\vartheta}_{y}\right)\right], \\
\frac{F_{d y}}{m}=-k_{d}\left[\dot{y}-\kappa \omega_{a} x-\frac{l}{5} \theta_{0}\left(\kappa \omega_{a} \vartheta_{y}+\dot{\vartheta}_{x}\right)\right], \\
\frac{M_{d x}}{m}=-k_{d} \frac{l}{5}\left[\theta_{0}\left(\dot{y}-\kappa \omega_{a} x\right)+\frac{l}{12}\left(\kappa \omega_{a} \vartheta_{y}+\dot{\vartheta}_{x}\right)\right], \\
\frac{M_{d y}}{m}=k_{d} \frac{l}{5}\left[\theta_{0}\left(\dot{x}+\kappa \omega_{a} y\right)+\frac{l}{12}\left(\kappa \omega_{a} \vartheta_{x}-\dot{\vartheta}_{y}\right)\right] ;
\end{gathered}
$$

forces and moments due to drop in pressure throttled on the groove seal $\Delta p_{0}$ (pressure flow), - 


$$
\begin{gathered}
\frac{F_{p x}}{m}=-k_{p}\left[\left(\theta_{0}+N \chi_{m}\right) x+(1+2 \Delta \chi) \frac{l}{2} \vartheta_{y}\right], \\
\frac{F_{p y}}{m}=-k_{p}\left[\left(\theta_{0}+N \chi_{m}\right) y-(1+2 \Delta \chi) \frac{l}{2} \vartheta_{x}\right], \\
\frac{M_{p x}}{m}=-k_{p} \frac{l}{6}\left[N \Delta \chi y-2 \chi_{m} \frac{l}{2} \vartheta_{x}\right], \\
\frac{M_{p y}}{m}=k_{p} \frac{l}{6}\left[N \Delta \chi x+2 \chi_{m} \frac{l}{2} \vartheta_{y}\right] .
\end{gathered}
$$

In formulas (1)-(6) let's move on to dimensionless coordinates and reduced forces and moments as well as let's introduce additional representations

$$
K_{i}=\frac{12 q_{0}}{H l(2-n)}, j=\frac{m l^{2}}{60 I},
$$

where $K_{i}$ - parameter considering local component of fluid inertia force; $j-$ dimensionless parameter characterizing the hydrodynamic moments in the groove seal; conversion the radial rigidity coefficients $k_{g}, k_{\mathrm{d}}, k_{p}$ into the corresponding angular rigidity coefficients $k_{g} j, k_{\mathrm{d}} j, k_{p} j, k_{p}=k_{p}^{\prime} / m H, M_{p x}^{*}=$ $=M_{p x} l / 2 H I=10 k_{p} j \chi_{m} \theta_{x}$.

Further the rotor rotating in two symmetrically located groove seals with fixed outer races $\left(\omega_{2}=0\right)$, is considered. Therefore, $\omega_{a}=0,5 \omega_{1}=0,5 \omega$, where $\omega_{1}=\omega-$ rotor speed. The values of forces and moments will be doubled by the number of seals. For convenience of further transformations, the components will be grouped according to their dependence on generalized coordinates $\left(F_{3}^{*}, M_{3}^{*}\right)$, generalized velocities $\left(F_{2}^{*}, M_{2}^{*}\right)$ and generalized accelerations $\left(F_{1}^{*}, M_{1}^{*}\right)$ :

$$
\begin{aligned}
-F_{1 x}^{*} & =2 k_{g} \ddot{u}_{x},-F_{1 y}^{*}=2 k_{g} \ddot{u}_{y},-M_{1 x}^{*}=-2 k_{g} j \ddot{\theta}_{x},-M_{1 y}^{*}=2 k_{g} j \ddot{\theta}_{y}, \\
-F_{2 x}^{*} & =2\left(k_{d}+k_{g} K_{i} \theta_{0}\right) \dot{u}_{x}+k_{g} \kappa \omega \dot{u}_{y}-\frac{2}{15} k_{g} \kappa \omega \theta_{0} \dot{\theta}_{x}+\frac{4}{5} k_{d} \theta_{0} \dot{\theta}_{y}, \\
-F_{2 y}^{*} & =-k_{g} \kappa \omega \dot{u}_{x}+2\left(k_{d}+k_{g} K_{i} \theta_{0}\right) \dot{u}_{y}-\frac{4}{5} k_{d} \theta_{0} \dot{\theta}_{x}-\frac{2}{15} k_{g} \kappa \omega \theta_{0} \dot{\theta}_{\mathrm{y}}, \\
& -M_{2 x}^{*}=j\left(2 k_{g} \kappa \omega \theta_{0} \dot{u}_{x}+12 k_{d} \theta_{0} \dot{u}_{y}+2 k_{d} \dot{\theta}_{x}+k_{g} \kappa \omega \dot{\theta}_{y}\right), \\
& -M_{2 y}^{*}=j\left(-12 k_{d} \theta_{0} \dot{u}_{x}+2 k_{g} \kappa \omega \theta_{0} \dot{u}_{y}-k_{g} \kappa \omega \dot{\theta}_{x}+2 k_{d} \dot{\theta}_{y}\right) ;
\end{aligned}
$$




$$
\begin{gathered}
-F_{3 x}^{*}=2 k_{\mathrm{p}}\left(\theta_{0}+N \chi_{m}\right) u_{x}+k_{d} \kappa \omega u_{y}-\frac{2}{5} k_{d} \kappa \omega \theta_{0} \theta_{x}+2 k_{p}(1+2 \Delta \chi) \theta_{y}, \\
-F_{3 y}^{*}=-k_{d} \kappa \omega u_{x}+2 k_{p}\left(\theta_{0}+N \chi_{m}\right) u_{y}-2 k_{p}(1+2 \Delta \chi) \theta_{x}-\frac{2}{5} k_{d} \kappa \omega \theta_{0} \theta_{y}, \\
-M_{3 x}^{*}=j\left(-6 k_{d} \kappa \omega \theta_{0} u_{x}+10 k_{p} N \Delta \chi u_{y}-20 k_{p} \chi_{m} \theta_{x}+k_{d} \kappa \omega \theta_{y}\right), \\
-M_{3 y}^{*}=j\left(-10 k_{p} N \Delta \chi u_{x}-6 k_{d} \kappa \omega \theta_{0} u_{y}-k_{d} \kappa \omega \theta_{x}-20 k_{p} \chi_{m} \theta_{y}\right) .
\end{gathered}
$$

Let's introduce notations of the doubled force coefficients

$$
\begin{gathered}
a_{11}=2 k_{g}, a_{21}=2\left(k_{d}+k_{g} K_{i} \theta_{0}\right), \\
a_{41}=k_{g} \kappa \omega, \alpha_{2}=\frac{2}{15} k_{g} \kappa \omega \theta_{0}, \alpha_{4}=\frac{4}{5} k_{d} \theta_{0}, \\
a_{31}=2 k_{p}\left(\theta_{0}+N \chi_{m}\right), a_{51}=k_{d} \kappa \omega, \\
\alpha_{3}=\frac{2}{5} k_{d} \kappa \omega \theta_{0}, \alpha_{5}=2 k_{p}(1+2 \Delta \chi) .
\end{gathered}
$$

Expressions of relative forces and moments for two groove seals now become:

$$
\begin{gathered}
-F_{1 x}^{*}=a_{11} \ddot{u}_{x},-F_{1 y}^{*}=a_{11} \ddot{u}_{y}, \\
-M_{1 x}^{*}=a_{11} \ddot{\theta}_{x},-M_{1 y}^{*}=a_{11} \ddot{\theta}_{y}, \\
-F_{2 x}^{*}=a_{21} \dot{u}_{x}+a_{41} \dot{u}_{y}-\alpha_{2} \dot{\theta}_{x}+\alpha_{4} \dot{\theta}_{y}, \\
-F_{2 y}^{*}-a_{41} \dot{u}_{x}+a_{21} \dot{u}_{y}-\alpha_{4} \dot{\theta}_{x}-\alpha_{2} \dot{\theta}_{y}, \\
-M_{2 x}^{*}=j\left[15 \alpha_{2} \dot{u}_{x}+15 \alpha_{4} \dot{u}_{y}+2 k_{d} \dot{\theta}_{x}+a_{41} \dot{\theta}_{y}\right], \\
-M_{2 y}^{*}=j\left[-15 \alpha_{4} \dot{u}_{x}+15 \alpha_{2} \dot{u}_{y}-a_{41} \dot{\theta}_{x}+2 k_{d} \dot{\theta}_{y}\right], \\
-F_{3 x}^{*}=a_{31} u_{x}+a_{51} u_{y}-\alpha_{3} \theta_{x}+\alpha_{5} \theta_{y},-F_{3 y}^{*}=-a_{51} u_{x}+a_{31} u_{y}-\alpha_{5} \theta_{x}-\alpha_{3} \theta_{\mathrm{y}}, \\
-M_{3 x}^{*}=j\left(-15 \alpha_{3} u_{x}+5 \alpha_{5} \frac{N \Delta \chi}{1+2 \Delta \chi} u_{y}-10 a_{31} \frac{\chi_{m}}{\theta_{0}+N \chi_{m}} \theta_{x}+a_{51} \theta_{y}\right), \\
-M_{3 y}^{*}=j\left(-5 \alpha_{5} \frac{N \Delta \chi}{1+2 \Delta \chi} u_{x}-15 \alpha_{3} u_{y}-a_{51} \theta_{x}-10 a_{31} \frac{\chi_{m}}{\theta_{0}+N \chi_{m}} \theta_{y}\right) .
\end{gathered}
$$

In the models of rotors of single-stage pumps, impellers are situated between two identical seals. For symmetrical statistically unbalanced rotors, for example rotors of double inlet impeller pump, radial oscillations are predomi- 
nant. Small angular oscillations are caused by unavoidable dynamic unbalance and probable disturbance of the rotor symmetry in regard to transverse vertical plane going through the center of masses. In this case, useful preliminary results can be received, when considering only radial oscillations. Herewith, the coefficients of hydrodynamic forces should be doubled (according to the number of seals).

Another extreme case of predominantly angular vibrations is possible for a symmetrical statically balanced rotor under the influence of dynamic unbalance. In this case, it is necessary to double the hydrodynamic moments. Besides, the radial hydrodynamic forces $F_{s u}^{*}$ arising when the rotor axis is skewed towards to the seal axis are different in value due to the difference in eccentricities, radial speeds and accelerations. Therefore, they create an additional moment relative to the center of impeller. The angles of azimuth in both seals with equally spaced bushings remain the same, therefore, the components of forces due to angular vibrations (with coefficients $\alpha_{i}$ ), do not create additional moments.

More details of additional moments from elastic forces are given in the paper [3]. For the right and left seals, dimensionless generalized coordinates, velocities and accelerations of the shaft center, which will be needed to calculate the moments of inertial, dissipative and gyroscopic forces, are written as:

$$
\begin{gathered}
u_{x}^{\prime}=u_{x}+\Delta u_{x}, u_{x}^{\prime \prime}=u_{x}-\Delta u_{x}, \Delta u_{x}=\frac{1}{H} l_{c} \vartheta_{y}=2 \frac{l_{c}}{l} \theta_{y} ; \\
u_{y}^{\prime}=u_{y}-\Delta u_{y}, u_{y}^{\prime \prime}=u_{y}+\Delta u_{y}, \Delta u_{y}=\frac{1}{H} l_{c} \vartheta_{x}=2 \frac{l_{c}}{l} \theta_{x} ; \\
\ddot{u}_{x}^{\prime}=\ddot{u}_{x}+\Delta \ddot{u}_{x}, \ddot{u}_{x}^{\prime \prime}=\ddot{u}_{x}-\Delta \ddot{u}_{x}, \Delta \ddot{u}_{x}=2 \frac{l_{c}}{l} \ddot{\theta}_{y} ; \\
u_{y}^{\prime}=u_{y}-\Delta u_{y}, u_{y}^{\prime \prime}=u_{y}+\Delta u_{y}, \Delta u_{y}=\frac{1}{H} l_{c} \vartheta_{x}=2 \frac{l_{c}}{l} \theta_{x} .
\end{gathered}
$$

Correlation $\theta_{x, y}=\vartheta_{x, y} l / 2 H$ is used here. The centripetal components are not indicated in the formulas for accelerations, since they are directed along the rotor axis and do not affect its radial-angular vibrations.

Based on (5), the dimensional forces in the right $F_{3}^{\prime}$ and left $F_{3}^{\prime \prime}$ seals are as follows:

$$
\begin{aligned}
& F_{3 x}^{\prime}=-m H \frac{a_{31}}{2}\left(u_{x}+\Delta u_{x}\right)=-F_{3 x}-\Delta F_{3 x}, \\
& F_{3 x}^{\prime \prime}=-\frac{a_{31}}{2} m H\left(u_{x}-\Delta u_{x}\right)=-F_{3 x}+\Delta F_{3 x},
\end{aligned}
$$




$$
\begin{gathered}
F_{3 y}^{\prime}=-m H \frac{a_{31}}{2}\left(u_{y}-\Delta u_{y}\right)=-F_{3 y}+\Delta F_{3 y}, \\
F_{3 y}^{\prime \prime}=-\frac{a_{31}}{2} m H\left(u_{y}+\Delta u_{y}\right)=-F_{3 y}-\Delta F_{3 y}, \\
\Delta F_{3 x}=a_{31} H m \frac{l_{c}}{l} \theta_{y}, \quad \Delta F_{3 y}=a_{31} H m \frac{l_{c}}{l} \theta_{x} .
\end{gathered}
$$

Additions to the forces are equal in value and oppositely directed, so their total projections on the corresponding axes are equal to zero and do not affect the radial vibrations.

Additional moments from elastic forces have the form:

$$
\begin{aligned}
& \Delta M_{3 x}=-2 l_{c} \Delta F_{3 y}=-2 a_{31} H m \frac{l_{c}^{2}}{l} \theta_{x}, \\
& \Delta M_{3 y}=-2 l_{c} \Delta F_{3 x}=-2 a_{31} H m \frac{l_{c}^{2}}{l} \theta_{y},
\end{aligned}
$$

and after dividing by the equatorial moment of inertia and multiplying by $l / 2 H$

$$
\begin{gathered}
\Delta M_{3 x}^{*}=\frac{\Delta M_{3 x} l}{2 H I}=-a_{31} j_{c} \theta_{x}, \\
\Delta M_{3 y}^{*}=\frac{\Delta M_{3 y} l}{2 H I}=-a_{31} j_{c} \theta_{y}, j_{c}=\frac{m l_{c}^{2}}{I} .
\end{gathered}
$$

Similarly, additional moments of other components of the radial force are calculated, due to the difference in generalized coordinates, velocities and accelerations (7) of the shaft centers in the right and left seals:

$$
\begin{gathered}
\Delta M_{1 x}^{*}=-a_{11} j_{c} \ddot{\theta}_{x}, \Delta M_{1 y}^{*}=-a_{11} j_{c} \ddot{\theta}_{y}, \\
\Delta M_{2 x}^{*}=-a_{21} j_{c} \dot{\theta}_{x}, \Delta M_{2 y}^{*}=-a_{21} j_{c} \dot{\theta}_{y}, \\
\Delta M_{4 x}^{*}=-a_{41} j_{c} \dot{\theta}_{y}, \Delta M_{4 y}^{*}=a_{41} j_{c} \dot{\theta}_{x}, \\
\Delta M_{5 x}^{*}=-a_{51} j_{c} \theta_{y}, \Delta M_{5 y}^{*}=a_{51} j_{c} \theta_{x} .
\end{gathered}
$$

The given additions depend on the angular coordinates, so they should be introduced into the moment components determined by the angles of rotation of the disk, angular velocities and accelerations. Having denoted total components of the hydrodynamic moment in two seals $M_{i(x, y)}=M_{i(x, y)}^{*}+\Delta M_{i(x, y)}^{*}$, $i=1,2,3$, taking into consideration (7)-(9) we shall obtain

$$
-M_{1 x}=a_{11}\left(j+j_{c}\right) \ddot{\theta}_{x},-M_{1 y}=a_{11}\left(j+j_{c}\right) \ddot{\theta}_{y} ;
$$




$$
\begin{gathered}
-M_{2 x}=15 j\left(\alpha_{2} \dot{u}_{x}+\alpha_{4} \dot{u}_{y}\right)+\left(2 k_{d} j+a_{21} j_{c}\right) \dot{\theta}_{x}+a_{41}\left(j+j_{c}\right) \dot{\theta}_{y}, \\
-M_{2 y}=15 j\left(-\alpha_{4} \dot{u}_{x}+\alpha_{2} \dot{u}_{y}\right)-a_{41}\left(j+j_{c}\right) \dot{\theta}_{x}+\left(2 k_{d} j+a_{21} j_{c}\right) \dot{\theta}_{y} ; \\
-M_{3 x}=j\left(-15 \alpha_{3} u_{x}+5 \alpha_{5} \frac{N \Delta \chi}{1+2 \Delta \chi} u_{y}\right)- \\
-a_{31}\left(\frac{10 \chi_{m}}{\theta_{0}+N \chi_{m}} j-j_{c}\right) \theta_{x}+a_{51}\left(j+j_{c}\right) \theta_{y}, \\
-M_{3 y}=j\left(-5 \alpha_{5} \frac{N \Delta \chi}{1+2 \Delta \chi} u_{x}-15 \alpha_{3} u_{y}\right)-a_{51}\left(j+j_{c}\right) \theta_{x}- \\
-a_{31}\left(\frac{10 \chi_{m}}{\theta_{0}+N \chi_{m}} j-j_{c}\right) \theta_{y} .
\end{gathered}
$$

It should be noted that additional moments were found for seals symmetrically located regarding the center of mass of the impeller. If this symmetry is violated, values $\Delta u_{x, y}(10)$ will slightly change, which will lead to a change in the numerical coefficient in expression of the parameter $j_{c}$.

Joint radial-angular oscillations of the rotor in groove seals. To analyze free oscillations, we use oscillation equation in projections without righthand sides [5]. For a constant, independent of the rotary velocity, differential pressure, the equations are written as

$$
\begin{aligned}
& a_{1} \ddot{u}_{x}+a_{2} \dot{u}_{x}+a_{3} u_{x}+\left(a_{4}^{\prime} \dot{u}_{y}+a_{5}^{\prime} u_{y}-\alpha_{2}^{\prime} \dot{\theta}_{x}-\alpha_{3}^{\prime} \theta_{x}\right) \omega+\alpha_{4} \dot{\theta}_{y}+\left(\alpha_{5}-\alpha_{0}\right) \theta_{y}=0, \\
& a_{1} \ddot{u}_{y}+a_{2} \dot{u}_{y}+a_{3} u_{y}-\left(a_{4}^{\prime} \dot{u}_{x}+a_{5}^{\prime} u_{x}+\alpha_{2}^{\prime} \dot{\theta}_{y}+\alpha_{3}^{\prime} \theta_{y}\right) \omega-\alpha_{4} \dot{\theta}_{x}-\left(\alpha_{5}-\alpha_{0}\right) \theta_{x}=0, \\
& b_{1} \ddot{\theta}_{x}+b_{2} \dot{\theta}_{x}+b_{3} \theta_{x}+\left(b_{4}^{\prime} \dot{\theta}_{y}+b_{5}^{\prime} \theta_{y}+\beta_{2}^{\prime} \dot{u}_{x}-\beta_{3}^{\prime} u_{x}\right) \omega+\beta_{4} \dot{u}_{y}+\left(\beta_{5}+\beta_{0}\right) u_{y}=0, \\
& b_{1} \ddot{\theta}_{y}+b_{2} \dot{\theta}_{y}+b_{3} \theta_{y}-\left(b_{4}^{\prime} \dot{\theta}_{x}+b_{5}^{\prime} \theta_{x}-\beta_{2}^{\prime} \dot{u}_{y}+\beta_{3}^{\prime} u_{y}\right) \omega-\beta_{4} \dot{u}_{x}-\left(\beta_{5}+\beta_{0}\right) u_{x}=0 .
\end{aligned}
$$

General solution of these homogeneous equations are written as:

$$
u_{x}=u_{a x} e^{\lambda \mathrm{t}}, \quad u_{y}=u_{a y} e^{\lambda \mathrm{t}}, \theta_{x}=\theta_{a x} e^{\lambda \mathrm{t}}, \theta_{y}=\theta_{a y} e^{\lambda \mathrm{t}} .
$$

Substituting the solution into the original equations, we arrive at algebraic equations in relation to the amplitudes of free oscillations:

$$
\begin{gathered}
\left(a_{1} \lambda^{2}+a_{2} \lambda+a_{3}\right) u_{a x}+\left(a_{4}^{\prime} \lambda+a_{5}^{\prime}\right) \omega u_{a y}- \\
-\left(\alpha_{2}^{\prime} \lambda+\alpha_{3}^{\prime}\right) \omega \theta_{a x}+\left(\alpha_{4} \lambda+\alpha_{5}-\alpha_{0}\right) \theta_{a y}=0,
\end{gathered}
$$




$$
\begin{gathered}
-\left(a_{4}^{\prime} \lambda+a_{5}^{\prime}\right) \omega u_{a x}+\left(a_{1} \lambda^{2}+a_{2} \lambda+a_{3}\right) u_{a y}- \\
-\left(\alpha_{4} \lambda+\alpha_{5}-\alpha_{0}\right) \theta_{a x}-\left(\alpha_{2}^{\prime} \lambda+\alpha_{3}^{\prime}\right) \omega \theta_{a y}=0, \\
\quad\left(\beta_{2}^{\prime} \lambda-\beta_{3}^{\prime}\right) \omega u_{a x}+\left(\beta_{4} \lambda+\beta_{5}+\beta_{0}\right) u_{a y}+ \\
+\left(b_{1} \lambda^{2}+b_{2} \lambda+b_{3}\right) \theta_{a x}+\left(b_{4}^{\prime} \lambda+b_{5}^{\prime}\right) \omega \theta_{y}=0, \\
-\left(\beta_{4} \lambda+\beta_{5}+\beta_{0}\right) u_{a x}+\left(\beta_{2}^{\prime} \lambda-\beta_{3}^{\prime}\right) \omega u_{a y}- \\
-\left(b_{4}^{\prime} \lambda+b_{5}^{\prime}\right) \omega \theta_{a x}+\left(b_{1} \lambda^{2}+b_{2} \lambda+b_{3}\right) \theta_{a y}=0 .
\end{gathered}
$$

The condition of existence of non-zero solutions is equality to zero of system determinant

$$
\Delta(\lambda)=
$$

$$
=\left|\begin{array}{cccc}
a_{1} \lambda^{2}+a_{2} \lambda+a_{3} & \left(a_{4}^{\prime} \lambda+a_{5}^{\prime}\right) \omega & -\left(\alpha_{2}^{\prime} \lambda+\alpha_{3}^{\prime}\right) \omega & \alpha_{4} \lambda+\alpha_{5}-\alpha_{0} \\
-\left(a_{4}^{\prime} \lambda+a_{5}^{\prime}\right) \omega & a_{1} \lambda^{2}+a_{2} \lambda+a_{3} & -\left(\alpha_{4} \lambda+\alpha_{5}-\alpha_{0}\right) & -\left(\alpha_{2}^{\prime} \lambda+\alpha_{3}^{\prime}\right) \omega \\
\left(\beta_{2}^{\prime} \lambda-\beta_{3}^{\prime}\right) \omega & \beta_{4} \lambda+\beta_{5}+\beta_{0} & b_{1} \lambda^{2}+b_{2} \lambda+b_{3} & \left(b_{4}^{\prime} \lambda+b_{5}^{\prime}\right) \omega \\
-\left(\beta_{4} \lambda+\beta_{5}+\beta_{0}\right) & \left(\beta_{2}^{\prime} \lambda-\beta_{3}^{\prime}\right) \omega & -\left(b_{4}^{\prime} \lambda+b_{5}^{\prime}\right) \omega & b_{1} \lambda^{2}+b_{2} \lambda+b_{3}
\end{array}\right|=0
$$

Having expanded the determinant, it is possible to obtain characteristic equation of 8 th degree in usual algebraic form in regard to the characteristic exponent $\lambda$.

To analyze joint radial-angular oscillations of the rotor, one has to use numerical methods. For numeric calculations it is more convenient to use dimensionless characteristic equations. That is why, let us divide (12) by $\Omega_{u 0}$ :

$$
\bar{\Delta}(\bar{\lambda})=\Delta(\lambda) / \Omega_{u 0}^{2}, \bar{\lambda}=\lambda / \Omega_{u 0}, \bar{\omega}=\omega / \Omega_{u 0} .
$$

The considered rotor in groove seals is an oscillatory system of the eighth order with four generalized coordinates: $u_{x}, u_{y}, \theta_{x}, \theta_{y}$. The system oscillates about a stable equilibrium position; therefore, the roots of characteristic equation are four pairs of complex adjoined numbers: $\lambda_{1}, \lambda_{1^{*}}, \lambda_{2}, \lambda_{2^{*}}, \lambda_{3}, \lambda_{3^{*}}, \lambda_{4}, \lambda_{4^{*}}$. Let's present them in expanded form:

$$
\left(\begin{array}{c}
\lambda_{1} \\
\lambda_{1^{*}}
\end{array}\right)=n_{1} \pm i s_{1},\left(\begin{array}{c}
\lambda_{2} \\
\lambda_{2^{*}}
\end{array}\right)=n_{2} \pm i s_{2},\left(\begin{array}{c}
\lambda_{3} \\
\lambda_{3^{*}}
\end{array}\right)=n_{3} \pm i s_{3},\left(\begin{array}{c}
\lambda_{4} \\
\lambda_{4^{*}}
\end{array}\right)=n_{4} \pm i s_{4} .
$$

Imaginary components $s_{k}$ of the roots are frequency of free oscillations and real-valued $n_{k}$ are relative damping ratios. Oscillations with increasing amplitude in time correspond to positive values $n_{k}>0$, i.e. the rotor loses stability; at $n_{k}=0 k$-th component of the oscillations has a constant amplitude, the rotor is on the oscillatory stability boundary. 
The pressure developed by the centrifugal stage is throttled on the front groove seal of the stage. This pressure is proportional to the square of the impeller rotary velocity: $\Delta p_{0}=\mathrm{B} \omega^{2}$. It is these conditions that are peculiar to centrifugal machines. As far as various equation coefficients (11) depend on pressure differential, they also depend on the frequency of rotation, and this depends on the form of frequency characteristics - dependencies of natural frequencies from the rotary speed. In this case, the pressure differential ceases to be an independent external influence, it is associated with additional correlation $\Delta p_{0}=\mathrm{B} \omega^{2}$. As a result, only the rotary speed is external influence, and self-intensification effect of the rotor is enhanced.

Forced joint radial-angular oscillations of the rotor at a constant pressure drop across the seals are described by equations [9]

$$
\begin{gathered}
a_{1} \ddot{u}+a_{2} \dot{u}+a_{3} u \mp i\left(a_{4}^{\prime} \dot{u}+a_{5}^{\prime} u\right) \omega-\left(\alpha_{2}^{\prime} \dot{\theta}+\alpha_{3}^{\prime} \theta\right) \omega \mp \\
\mp i\left(\alpha_{4} \dot{\theta}+\alpha_{5} \theta-\alpha_{0} \theta\right)=\omega^{2} a^{*}=\omega^{2}\left|a^{*}\right| e^{ \pm i \omega t}, \\
b_{1} \ddot{\theta}+b_{2} \dot{\theta}+b_{3} \theta \mp i\left(b_{4}^{\prime} \dot{\theta}+b_{5}^{\prime} \theta\right) \omega+\left(\beta_{2}^{\prime} \dot{u}-\beta_{3}^{\prime} u\right) \omega \mp \\
\mp i\left(\beta_{4} \dot{u}+\beta_{5} u+\beta_{0} u\right)=\left(1-j_{0}\right) \omega^{2} \gamma^{*}=\left(1-j_{0}\right) \omega^{2}\left|\gamma^{*}\right| e^{ \pm i \omega t} ;
\end{gathered}
$$

Using standard programs, you can immediately find numerical solution of these equations:

$$
\begin{gathered}
a_{1} \ddot{u}+a_{2} \dot{u}+a_{3} u-i\left(a_{4}^{\prime} \dot{u}+a_{5}^{\prime} u\right) \omega-\left(\alpha_{2}^{\prime} \dot{\theta}+\alpha_{3}^{\prime} \theta\right) \omega- \\
-i\left(\alpha_{4} \dot{\theta}+\alpha_{5} \theta-\alpha_{0} \theta\right)=\omega^{2} A e^{i \omega t}, \\
b_{1} \ddot{\theta}+b_{2} \dot{\theta}+b_{3} \theta-i\left(b_{4}^{\prime} \dot{\theta}+b_{5}^{\prime} \theta\right) \omega+\left(\beta_{2}^{\prime} \dot{u}-\beta_{3}^{\prime} u\right) \omega- \\
-i\left(\beta_{4} \dot{u}+\beta_{5} u+\beta_{0} u\right)=\omega^{2} \Gamma e^{i \omega t} .
\end{gathered}
$$

Substituting the solution of these equations in the form

$$
u=u_{a} e^{i\left(\omega t+\phi_{u}\right)}=\tilde{u} e^{i \omega t}, \theta=\theta_{a} e^{i\left(\omega t+\phi_{\vartheta}\right)}=\tilde{\theta} e^{i \omega t},
$$

we shall obtain a system of algebraic equations for complex amplitudes $\mathrm{A}$ and $\Gamma$ :

$$
\begin{gathered}
{\left[-a_{1} \omega^{2}+a_{3}+a_{4}^{\prime} \omega^{2}+i\left(a_{2}-a_{5}^{\prime}\right) \omega\right] \tilde{u}-} \\
-\left[\left(\alpha_{3}^{\prime}-\alpha_{4}\right) \omega+i\left(\alpha_{2}^{\prime} \omega^{2}+\alpha_{5}-\alpha_{0}\right)\right] \tilde{\theta}=\mathrm{A} \omega^{2}, \\
{\left[-\left(\beta_{3}^{\prime}-\beta_{4}\right) \omega+i\left(\beta_{2}^{\prime} \omega^{2}-\beta_{5}-\beta_{0}\right)\right] \tilde{u}+} \\
+\left[-b_{1} \omega^{2}+b_{3}+b_{4}^{\prime} \omega^{2}+i\left(b_{2}-b_{5}^{\prime}\right) \omega\right] \tilde{\theta}=\Gamma \omega^{2} .
\end{gathered}
$$


Let's move on to dimensionless frequencies $\bar{\omega}=\omega / \Omega_{u 0}$ and introduce the notation:

$$
\begin{gathered}
U_{11}=\left(-a_{1}+a_{4}^{\prime}\right) \bar{\omega}^{2}+1+\frac{a_{31}}{\Omega_{u 0}^{2}}, V_{11}=\frac{a_{20}+a_{21}-a_{5}^{\prime}}{\Omega_{u 0}} \bar{\omega}, \\
U_{12}=\frac{-\alpha_{3}^{\prime}+\alpha_{4}}{\Omega_{u 0}} \bar{\omega}, V_{12}=-\alpha_{2}^{\prime} \bar{\omega}^{2}-\frac{\alpha_{5}-\alpha_{0}}{\Omega_{u 0}^{2}} ; \\
U_{21}=\frac{-\beta_{3}^{\prime}+\beta_{4}}{\Omega_{u 0}} \bar{\omega}, V_{21}=\beta_{2}^{\prime} \bar{\omega}^{2}-\frac{\beta_{5}+\beta_{0}}{\Omega_{u 0}^{2}}, \\
U_{22}=\left(-b_{1}+b_{4}^{\prime}\right) \bar{\omega}^{2}+\frac{\Omega_{90}^{2}}{\Omega_{u 0}^{2}}+\frac{b_{31}}{\Omega_{u 0}^{2}}, \\
V_{22}=\frac{b_{20}+b_{21}-b_{5}^{\prime}}{\Omega_{u 0}} \bar{\omega} .
\end{gathered}
$$

Then, these equations (13) become

$$
\begin{aligned}
& \left(U_{11}+i V_{11}\right) \tilde{u}+\left(U_{12}+i V_{12}\right) \tilde{\theta}=\mathrm{A} \bar{\omega}^{2}, \\
& \left(U_{21}+i V_{21}\right) \tilde{u}+\left(U_{22}+i V_{22}\right) \tilde{\theta}=\Gamma \bar{\omega}^{2} .
\end{aligned}
$$

Here $U_{11}+i V_{11}, U_{22}+i V_{22}$ are proper operators of the independent radial and angular oscillations correspondingly. Cross sectional operators $U_{12}+i V_{12}$, $U_{21}+i V_{21}$ characterize the influence of angular oscillations on radial and the effect of radial on angular, i.e., interconnection of these oscillations.

Determination of the amplitude and phase frequency characteristics. From the system of non-homogenous algebraic equations (14) according to Cramer's formulas [8] we find complex amplitudes

$$
\tilde{u}=\bar{\omega}^{2} \frac{\Delta_{u}}{\Delta_{0}}, \tilde{\theta}=\bar{\omega}^{2} \frac{\Delta_{\vartheta}}{\Delta_{0}},
$$

where system determinant $\Delta_{0}$ and determinants $\Delta_{u}, \Delta_{\vartheta}$ are written as

$$
\begin{gathered}
\Delta_{0}=U_{0}+i V_{0} ; \\
U_{0}=U_{11} U_{22}-V_{11} V_{22}-U_{12} U_{21}+V_{12} V_{21}, \\
V_{0}=V_{11} U_{22}+U_{11} V_{22}-V_{12} U_{21}-U_{12} V_{21}, \\
\Delta_{u}=U_{u}+i V_{u} ; \\
U_{u}=\mathrm{A} U_{22}-\Gamma U_{12}, V_{u}=\mathrm{A} V_{22}-\Gamma V_{12} ; \\
\Delta_{\vartheta}=U_{\vartheta}+i V_{\vartheta} ; \\
U_{\vartheta}=\Gamma U_{11}-\mathrm{A} U_{21}, V_{\vartheta}=\Gamma V_{11}-\mathrm{A} V_{21} .
\end{gathered}
$$


Taking into consideration the reported values of formula determinants (15), upon division of real and imaginary parts, the following is given:

$$
\begin{gathered}
\tilde{u}=u_{a} e^{i \phi_{u}}=\bar{\omega}^{2} \frac{U_{1}-i V_{1}}{U_{0}^{2}+V_{0}^{2}} ; \\
U_{1}=U_{u} U_{0}+V_{u} V_{0}, V_{1}=U_{u} V_{0}-V_{u} U_{0} ; \\
\tilde{\theta}=\theta_{a} e^{i \varphi_{\vartheta}}=\bar{\omega}^{2} \frac{U_{2}-i V_{2}}{U_{0}^{2}+V_{0}^{2}} ; \\
U_{2}=U_{\vartheta} U_{0}+V_{\vartheta} V_{0}, V_{2}=U_{\vartheta} V_{0}-V_{\vartheta} U_{0} .
\end{gathered}
$$

Modules and arguments of complex amplitudes

$$
\begin{gathered}
u_{a}=\bar{\omega}^{2} \frac{\sqrt{U_{1}^{2}+V_{1}^{2}}}{U_{0}^{2}+V_{0}^{2}}=\bar{\omega}^{2} \sqrt{\frac{U_{u}^{2}+V_{u}^{2}}{U_{0}^{2}+V_{0}^{2}}}, \\
\theta_{a}=\bar{\omega}^{2} \frac{\sqrt{U_{2}^{2}+V_{2}^{2}}}{U_{0}^{2}+V_{0}^{2}}=\bar{\omega}^{2} \sqrt{\frac{U_{\vartheta}^{2}+V_{\vartheta}^{2}}{U_{0}^{2}+V_{0}^{2}}} \\
\phi_{u}=-\operatorname{arctg} \frac{V_{1}}{U_{1}}=-\operatorname{arctg} \frac{U_{u} V_{0}-V_{u} U_{0}}{U_{u} U_{0}+V_{u} V_{0}} \\
\phi_{\vartheta}=-\operatorname{arctg} \frac{V_{2}}{U_{2}}=-\operatorname{arctg} \frac{U_{\vartheta} V_{0}-V_{\vartheta} U_{0}}{U_{\vartheta} U_{0}+V_{\vartheta} V_{0}} .
\end{gathered}
$$

Having substituted the values of determinants (16), (17) in these formulas (18), we shall obtain amplitudes and phases, expressed in terms of external disturbances:

$$
\begin{gathered}
u_{a}=\bar{\omega}^{2} \sqrt{\frac{\left(\mathrm{A} U_{22}-\Gamma U_{12}\right)^{2}+\left(\mathrm{A} V_{22}-\Gamma V_{12}\right)^{2}}{U_{0}^{2}+V_{0}^{2}}}, \\
\theta_{a}=\bar{\omega}^{2} \sqrt{\frac{\left(\Gamma U_{11}-\mathrm{A} U_{21}\right)^{2}+\left(\Gamma V_{11}-\mathrm{A} V_{21}\right)^{2}}{U_{0}^{2}+V_{0}^{2}}}, \\
\phi_{u}=-\operatorname{arctg} \frac{\left(\mathrm{A} U_{22}-\Gamma U_{12}\right) V_{0}-\left(\mathrm{A} V_{22}-\Gamma V_{12}\right) U_{0}}{\left(\mathrm{~A} U_{22}-\Gamma U_{12}\right) U_{0}+\left(\mathrm{A} V_{22}-\Gamma V_{12}\right) V_{0}}, \\
\phi_{\vartheta}=-\operatorname{arctg} \frac{\left(\Gamma U_{11}-\mathrm{A} U_{21}\right) V_{0}-\left(\Gamma V_{11}-\mathrm{A} V_{21}\right) U_{0}}{\left(\Gamma U_{11}-\mathrm{A} U_{21}\right) U_{0}+\left(\Gamma V_{11}-\mathrm{A} V_{21}\right) V_{0}} .
\end{gathered}
$$


Using formulas (19), we can build amplitude frequency characteristics as amplitude ratio of the corresponding oscillations to the amplitudes of external excitements:

$$
A_{u a}=\frac{u_{a a}}{\mathrm{~A}}, A_{\vartheta a}=\frac{\theta_{a a}}{\mathrm{~A}}, A_{u \gamma}=\frac{u_{a \gamma}}{\Gamma}, A_{\vartheta \gamma}=\frac{\theta_{a \gamma}}{\Gamma} .
$$

Numerical calculations were carried out for the rotor model with a disc between the bearings. The groove seals with three taper parameters were considered: $\theta_{0}=-0,3 ; 0 ; 0,3$. Diagrams for these parameters in Fig. 4, 5 are designated respectively by numbers $1,2,3$. Calculations were carried out for constant pressure differences $\Delta p_{0}=(1,5 ; 4,0 ; 13,3) \mathrm{MPa}$. The following values of unbalance were considered in the calculations: $A=a^{*}=a / H=0,05$, $a=12,5 \mu \mathrm{m}, a \omega_{n}=3,75 \mathrm{~mm} / \mathrm{s}$,

Fig. 4 and 5 show the amplitude-frequency characteristics for pressure differentials that do not depend on the rotor speed: the preset pressure differential is created by an independent external source.

The differences in the patterns of rotor oscillations in groove seals in air are caused by the action of hydrodynamic forces arising in groove seals. The force of inertia $\left(a_{1}\right)$ and the force of viscous resistance $\left(a_{2}\right)$ decrease, while the gyroscopic force $\left(a_{4}\right)$ and the force of hydrostatic rigidity $\left(a_{31}\right)$ increase the modules of natural frequencies $\left(s_{u}\right)$. The increase in natural frequen-cies is proportional to the square root of differential pressure throttled across the seals and depends on the taper of annular throttling gap. For typical designs of centrifugal pumps, natural frequencies of the rotors in seals with a confuser $\left(\theta_{0}=0,3\right)$ channel are 2-4 times higher than in diffuser $\left(\theta_{0}=-0,3\right)$ seals. The pressure differential of $1.5 \mathrm{MPa}$ across the converging seals provides almost threefold increase in natural frequency of the rotor. This confirms the possibility and effectiveness of simultaneous use of groove seals as hydrostatic bearings, and hence the prospectivity of pump designs without external oil bearings.

The circulation force $\left(a_{5}\right)$, depending on the rotary speed, does not affect the value of natural frequencies, but decreases the module of relative damping ratio $\left(n_{u}\right)$. Therefore, it is the main destabilizing factor and leading to the loss of stability of free oscillations. The circulation force is proportional to the swirling ratio of flow in the annular channel; therefore, swirling suppression expands the rotor stability region.

The hydrodynamic dissipative force depends on the channel taper and can change sign in the diffuser channel, turning into a force of negative resistance, i.e. is another destabilizing factor. Unlike the circulating force due to proper 

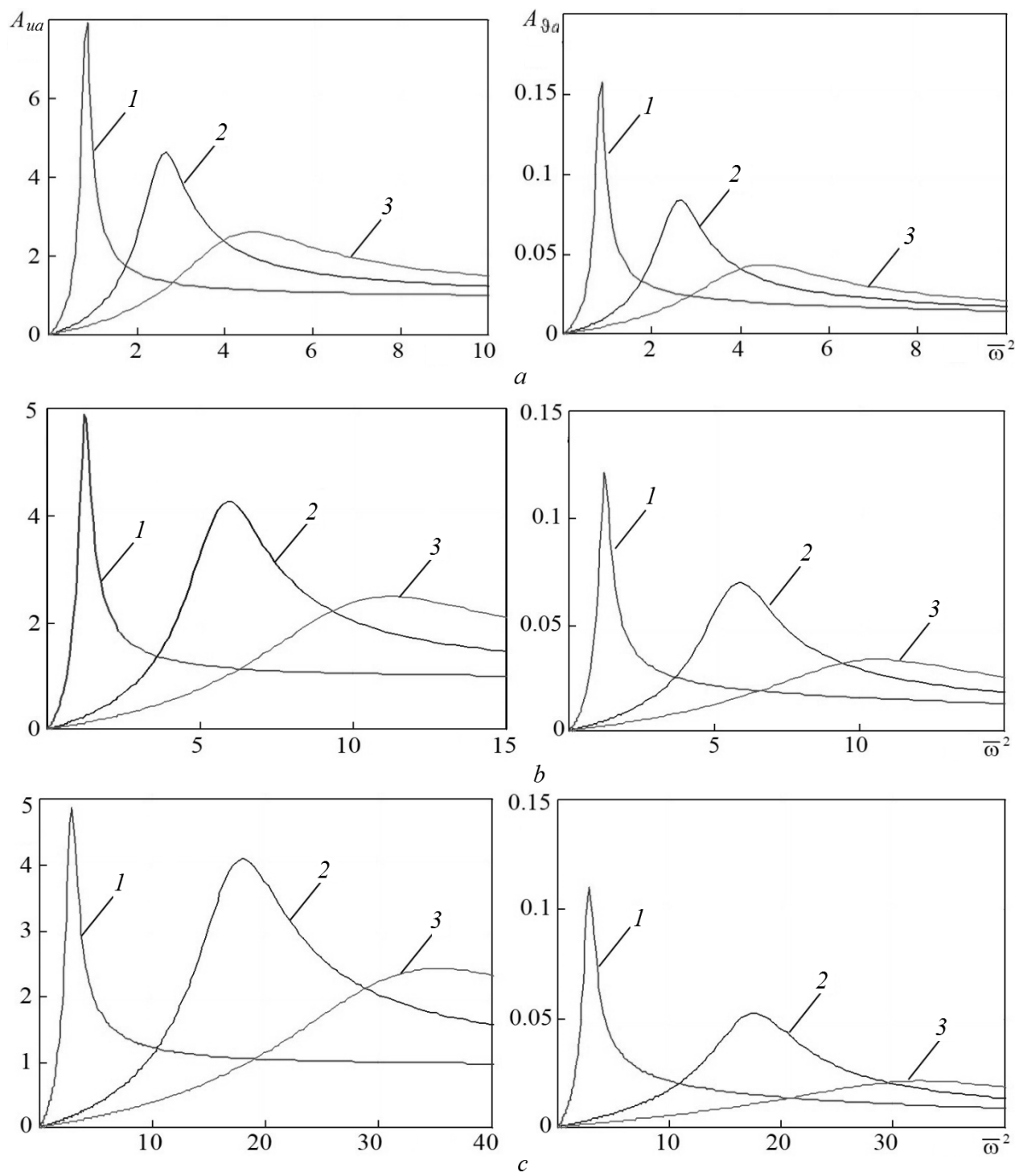

Fig. 4. Amplitude-frequency characteristics as a response to statistic unbalance, model $P-1: a-$ $\Delta p_{0}=1,5 \mathrm{MPa}=$ const, $b-\Delta p_{0}=4 \mathrm{MPa}=$ const, $c-\Delta p_{0}=13,3 \mathrm{MPa}=$ const

rotation of the rotor, the dissipative force does not depend on rotary speed and can become negative in the absence of rotation. Thus, in seals with diffuser channels, even a non-rotating rotor can go beyond oscillatory stability.

Force factors of the groove seals are determined by the geometric (gap, radius, length, taper, shape of the input edges) and operational (pressure dif- 

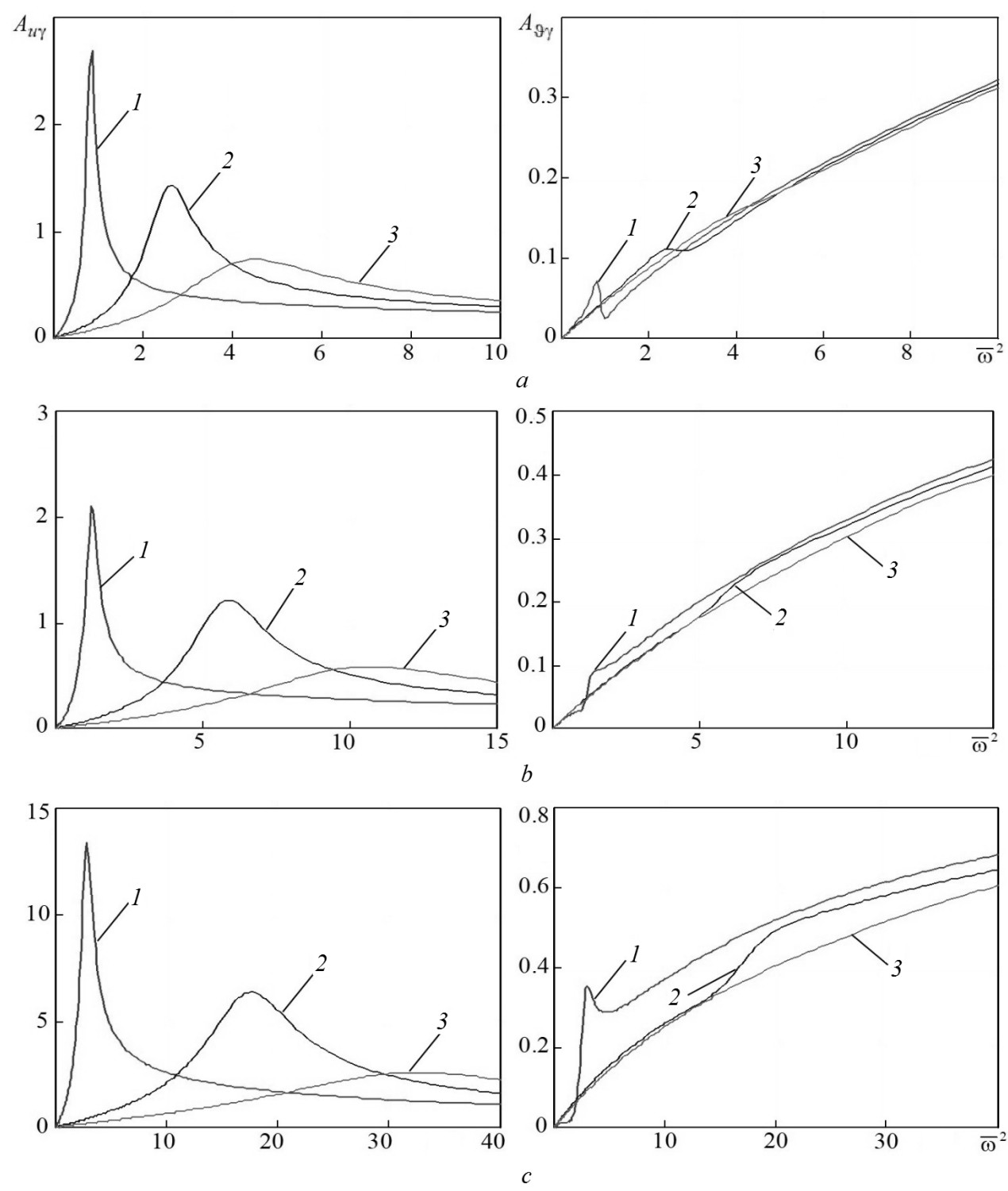

Fig. 5. Amplitude-frequency characteristics as a response to dynamic unbalance, model $P-1$ : $a-\Delta p_{0}=1,5 \mathrm{MPa}=$ const, $b-\Delta p_{0}=4 \mathrm{MPa}=$ const, $c-\Delta p_{0}=13,3 \mathrm{MPa}=$ const

ferential, operating speed range, physical properties of the pumped medium) parameters. A purposeful choice of these parameters can influence vibratory condition of the rotor and the machine as a whole.

The important feature of centrifugal machines is that the pressure differentials throttled on the groove seals are proportional to the rotor speed. This is 
due to self-intensification effect of the rotor, which leads to the fact that in most cases there are no critical frequencies. Self- intensification is enhanced by gyroscopic moments of groove seals, and for rotors of a disk design - by gyroscopic moment of a disk.

\section{Conclusion}

Based on the study of hydromechanical model of groove seal and models of rotors in groove seals, analytical dependences that describe the radial-angular vibrations of the rotor are obtained.

Force coefficients of groove seals are determined by geometric (clearance, radius, length, taper, shape of the input edges) and operational (pressure drop, operating speed range, physical properties of the pumped medium) parameters. A purposeful choice of these parameters can influence the vibration state of the rotor and the machine itself. An important feature of centrifugal machines is that the pressure drops that throttled on the groove seals are proportional to the rotor speed.

This is especially important for machines with high parameters. For example, in space technology, where high shaft speeds and sealing pressure must be provided in combination with the requirement to minimize the weight and dimensions of the unit. That is, the initially "flexible" in the dynamic sense rotor, in combination with properly designed seals, becomes "tough".

\section{REFERENCES}

1. Martsynkivskyi, V.A. and Shevchenko, S.S. (2018, Nasosy atomnykh elektrostantsiy. Raschet. Konstruirovaniye. Ekspluatatsiya [Pumps of nuclear power plants: calculation, design, operation], Izd-vo «Universitetskaya kniga», Sumy, Ukraine.

2. Korchak, A., Martsynovskyi, V.A., Churylova V.E. (2003), "Static calculation of angularcontact hydrostatic self-adjusting bearings", Visnyk Tekhnolohichnoho universytetu Podillya, Vol. 1, no. 1, pp. 196-201.

3. Martsynovskyi, V.A. (2005), Shchelevyye uplotneniya: teoriya i praktika [Groove seals: theory and practice], Izd-vo Sumskogo univesiteta, Sumy, Ukraine.

4. Martsynovskyi, V.A. (1995), "Radial-angular oscillations of the centrifugal machine rotor in the groove bearings-seals", Zeszyty naukowe politechniki Swiętokrzyskiej, pp. 247-259.

5. Tymoshenko, S.P., Yang, D.Kh. and Uiver, U. (1985), Kolebaniya $v$ inzhenernom dele [Oscillations in engineering], Mashinostroyeniye, Moscow, USSR.

6. Korczak, A., Marcinkowski, W. and Peczkis, G. (2007), "Wpływ szczelin uszczelniających na dynamikę zespołu wirującego pompy odśrodkowej”, Politechnika śląska. Prace naukowe, Vol. 18, pp. 161-170.

7. Kundera, Cz. and Marcinkowski, W. (2010), "The effect of the annular seal parameters on the dynamics of the rotor system", Int. Journal of Applied Mechanics and Engineering, Vol. 15, no 3, pp. 719-730.

8. Marcinkowski W. and Kundera Cz. (2008), Teoria konstrukcji uszczelnien bezstykowych [The theory of construction of non-contact seals], Wyd-wo Politechniki Swiętokrzyskiej, Kielce, Poland. 
9. Yamamoto T. and Ishida Y. (2001), Linear and nonlinear rotor dynamics. A modern treatment with applications, John Willey\&Sons, New York, USA.

10. Martsynovskyi, V.A. (2012), Dinamika rotorov tsentrobezhnykh mashin [Dynamics of the centrifugal machine rotors], Izd-vo Sumskogo univesiteta, Sumy, Ukraine.

Received on 19.04.21; after revision 14.05.21

\section{С.С. Шевченко}

\section{МАТЕМАТИЧНЕ МОДЕЛЮВАННЯ ДИНАМІЧНОЇ СИСТЕМИ РОТОР - ЩІЛИННІ УЩІЛЬНЕННЯ}

Із зростанням параметрів обладнання, таких як тиск ущільнюваного середовища і швидкість обертання ротора, зростають і проблеми, пов'язані із забезпеченням ефективності його герметизації. Крім власне герметизації системи ущільнення впливають на загальну експлуатаційну безпеку обладнання, особливо вібраційну. Щілинні ущільнення розглядаються як гідростатодинамічні опори, здатні ефективно демпфувати коливання ротора. Для визначення динамічних характеристик розглянута модель системи ротор - щілинні ущільнення, моделі однодискових роторів, розрахункова схема щілинного ущільнення 3 рухомою втулкою. Наведено отримані аналітичні залежності для розрахунку динамічних характеристик гідромеханічної системи, що описують радіально-кутові коливання ротора відцентрової машини в щілинних ущільненнях, а також формули для розрахунку амплітудних частотних характеристик. Наведено приклад розрахунку динамічних характеристик однієї з моделей ротора відцентрової машини.

Клю ч о в $і$ с ло в а: ущільнення-опори, радіально-кутові коливання, частотні характеристики.

SHEVCHENKO Serhii Stanislavovych, PhD in Technical Sciences, senior research officer, Pukhov Institute for Modelling in Energy Engineering of the National Academy of Sciences of Ukraine. In 1984 he graduated from Sumy Branch of Kharkiv Polytechnic Institute. Researches in the issues of germomechanics using the achievements of tribomechanics, elasticity theory, oscillation theory, fluid dynamics, theory of optimization of hydrodynamic systems. 